\title{
Sulfonated Poly(aryl ether ketone) Random Copolymers Having Crosslinking Structure for Proton Exchange Membrane of Fuel Cell
}

\author{
By Satoko FuJIYAMa, ${ }^{*}$ Junichi ISHIKAWA, Takehiko OMI, and Shoji TAMAI
}

We have succeeded in developing a new methodology for proton exchange membrane (PEM) of direct methanol fuel cell (DMFC), which stemmed formation of a crosslinking structure by UV irradiation to sulfonated poly (aryl ether ketone) (PAEK) copolymer. A new class of the aromatic PAEKs with pendant sulfonate groups and methyl groups have been prepared by a direct aromatic nucleophilic substitution polycondensation reaction of 3,3'-disulfonated-4,4'-difluorobenzophenone (DSDFBP), 4,4'-difluorobenzophenone (DFBP) and the biphenols that have methyl groups. The polymerization quantitatively proceeded to form a high intrinsic viscosity of copolymer. Membranes having high mechanical strength were successfully obtained from the copolymers of DSDFBP, DFBP and the biphenols that have methyl groups including tetramethyl bisphenol A (TMBPA), tetramethyl bisphenol F (TMBPF) and tetramethyl biphenol (TMBP). The ketone of benzophenone group and the methyl group in the repeating structure unit of these PAEKs were easily crosslinked by UV irradiation and induced a crosslinked structure that improved their methanol blocking properties drastically. The membrane of crosslinking copolymer, DSDFBP/DFBP/TMBPF $=5 / 5 / 10$ mole ratio (F1), was stable at $240{ }^{\circ} \mathrm{C}$ in air and showed the high proton conductivity at $90^{\circ} \mathrm{C}$ of $0.23 \mathrm{~S} / \mathrm{cm}$ and the low methanol permeation rate at $25^{\circ} \mathrm{C}$ of $5.5 \mu \mathrm{mol} / \mathrm{cm}^{2} / \mathrm{min}$. This proton conductivity and methanol permeability are comparable to and half of the values of fluorinated copolymer Nafion $112^{\circledR}$ that is known as the representative material of a PEM of DMFC respectively. These new copolymers, which have proton conductive sites and crosslinking structures, are candidates as new polymeric electrolyte materials for proton exchange membrane fuel cells, especially for DMFCs.

KEY WORDS: Sulfonated Poly(aryl ether ketone) / Crosslink / Proton Exchange Membrane / Fuel Cell /

The large interest in using polymer electrolyte membrane fuel cells (PEMFCs) as power sources of vehicles or portable applications has been greatly promoted these years. Among many kinds of PEMFCs, direct methanol fuel cells (DMFCs) are promising candidates for portable power sources and transport applications because they don't require fuel process equipment (such as reformers or catalytic burners) and can be operated at room temperature.

A DMFC consists of a proton exchange membrane (PEM) sandwiched between an anode and a cathode. The PEM for DMFC requires three major functions, as a proton conductor, as a fuel barrier and as a mechanical separator between the two electrodes. Nafion ${ }^{\circledR}$ that is known as a superior membrane for PEMFC has high proton conductivity and suitable mechanical strength. However, methanol goes through the Nafion ${ }^{\circledR}$ membrane, so that a large amount of methanol is lost in the DMFC. This is so-called "methanol crossover." To improve DMFC performance, the high methanol blocking property is required while the proton conductivity, the thermo oxidation stability and the mechanical strength are maintained. Methanol permeates through the ionic channels of membranes and the size of these channels increases as swelling of the membrane increases. Thus the easiness of swelling of the membrane caused permeation of methanol easily. Therefore, it becomes necessary to suppress the swelling of membrane by methanol to get the low methanol permeability. In general, suppressing the swelling of membrane is a cause of reduction of the proton conductivity. So, the balance of the value of methanol permeate with the value of proton conductivity is important.

Several attempts have been made to limit the swelling by pore-filling method or crosslinking method. Yamaguchi ${ }^{1}$ investigated pore-filling electrolyte membranes for use as PEM in DMFC. Although the membranes having pores filled with a polymer electrolyte can control methanol permeation, non-conductivity of the porous substrate caused decreasing of proton conductivity. For an example of crosslinking method, Yen $^{2}$ reported the crosslinking of sulfonate groups among themselves enhanced protection of methanol crossover. However, the decreasing of sulfonate groups caused decreasing of proton conductivity, and the chemical reaction of sulfonate groups was caused voids in the membrane. ${ }^{3}$ Moreover, Yoshida ${ }^{4}$ proposed crosslinking of $\mathrm{Nafion}^{\circledR}$ by radioactive rays. This method was effective to protect methanol crossover, but radioactive rays gave damages to the membrane.

Economical and commercially viable engineering polymers have been focused on as PEMs for fuel cells because of their high thermo oxidation stability and high solvent resistance. Concerning synthetic methods of sulfonated polymers, many groups have been investigating postsulfonated aromatic polymers. The postsulfonation of polymers has been accomplished using sulfonation agents such as chlorosulfonic acid, ${ }^{5}$ sulfonic acid $^{6-8}$ and sulfur trioxide/triethyl phosphate complexes ${ }^{9}$ etc. 
However, in the case of the postsulfonation of polymers, undesirable chain scission, branching and crosslinking can occur with chlorosulfonic acid, and also decrease in the molecular weight and partial gelation are observed with sulfonic acid. In order to control the positions and the quantity of sulfonate groups, the monomer sulfonation and the subsequent controlled copolymerization are quite suitable. Wang ${ }^{10}$ reported the sulfonation of $4,4^{\prime}$-difluorobenzophenone (DFBP) with coplymerization of 3,3'-disulfonated-4,4'-difluorobenzophenone(DSDFBP), DFBP and bisphenolA(BPA) to generate copolymer with up to $40 \mathrm{~mol} \%$ DSDFBP. This approach allows for the much better control of the position and the degree of sulfonation.

We have designed a new approach, whose key step, our own technology, is the formation of a crosslinking structure by UV irradiation to sulfonated poly (aryl ether ketone) (PAEK) copolymer shown in Figure 1. The technology was reported as the method for the introduction of a crosslinked structure to the PAEK having a benzophenone group and an alkyl group in the repeating structure unit by Goto. ${ }^{11} \mathrm{We}$ anticipated that the most suitable balance of methanol permeation and proton conductivity can be achieved through introduction of crosslinking by UV irradiation and control of the position and quantity of sulfonated groups. We have chosen the PAEK having methyl groups and pendant sulfoate groups in the repeating structure unit because of in particular excellent chemical property of PAEK. This repeating structure unit has the benzophenone groups and methyl groups readily crosslinkable by UV irradiation and the degree of sulfonation is controlled by quantity of sulfonated monomer. The sulfonation extent and the degree of crosslinking were carefully controlled so as to maximize the proton conductivity and to minimize the methanol crossover. In this paper, the effects of the repeating structures and the degree of crosslinking are investigated by assessing performances of membranes and characters of their structures.

\section{EXPERIMENTAL}

\section{Materials}

$50 \%$ Fuming sulfuric acid, sodium hydroxide $(\mathrm{NaOH})$, sodium chloride $(\mathrm{NaCl})$ and ethanol were obtained from Wako Pure Chemical Industries, Ltd.

4,4'-Difluorobenzophenone (DFBP), tetramethyl bisphenol A (TMBPA), tetramethyl bisphenol $F$ (TMBPF) and tetramethyl biphenol (TMBP) were obtained from Tokyo Kasei Industries, Ltd. (TCI) were used as received (Figure 2). Anhydrous dimethylsulfoxide (DMSO) and toluene were obtained from Wako Pure Chemical Industries, Ltd. Potassium carbonate was obtained from Tokuyama Co., Ltd., and dried at $150{ }^{\circ} \mathrm{C}$ for $12 \mathrm{~h}$ under nitrogen.

\section{Synthesis of Disodium Salt of DSDFBP}

A modified procedure from previously reported approaches $^{10}$ was developed and used for the synthesis of DSDFBP from DFBP. A typical procedure is as follows:
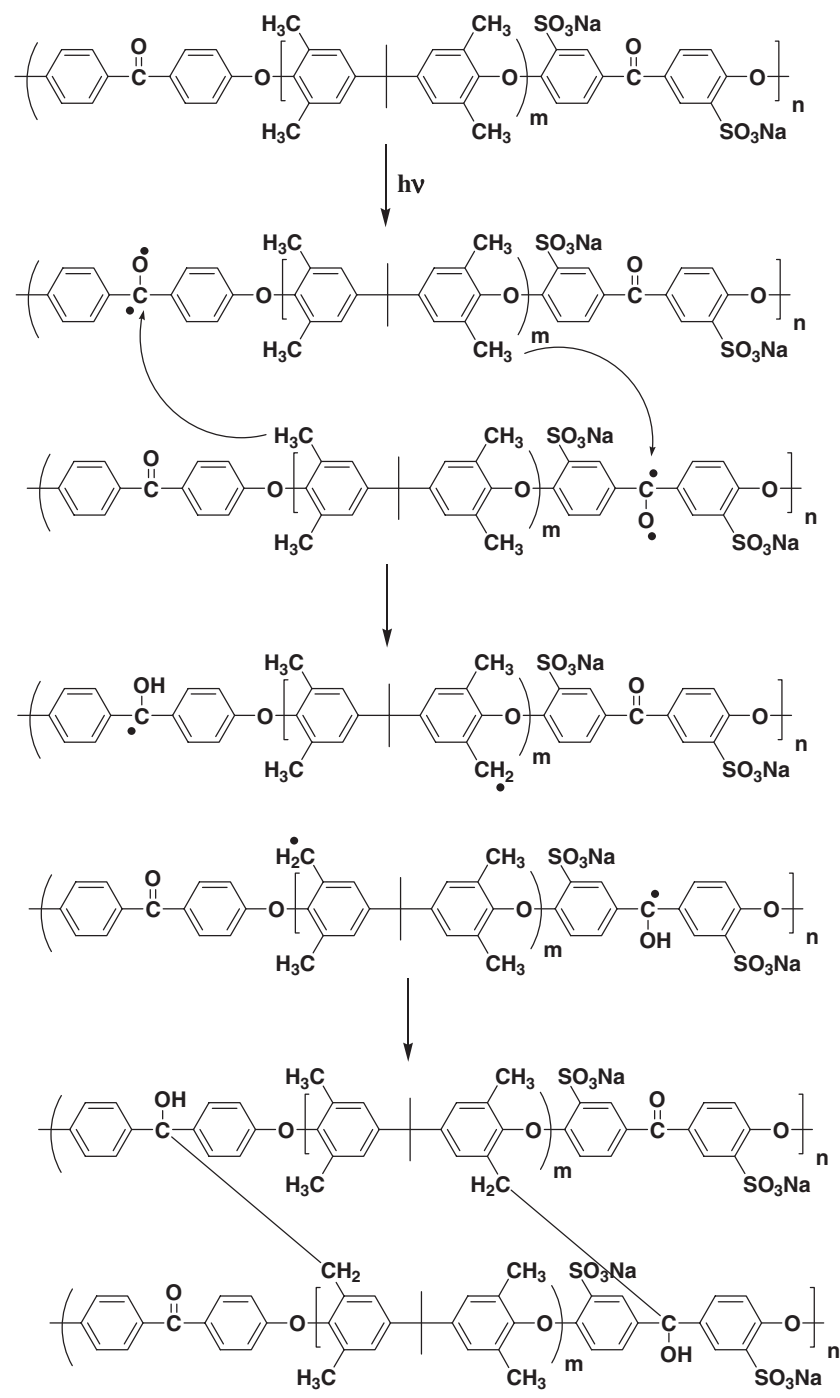

Figure 1. UV crosslinking of poly (aryl ether ketone) having benzophenoe and alkyl group.<smiles>Cc1cc(C(C)(C)c2cc(C)c(O)c(C)c2)cc(C)c1O</smiles>

Tetramethyl bisphenol A (TMBPA)<smiles>Cc1cc(Cc2cc(C)c(O)c(C)c2)cc(C)c1O</smiles>

Tetramethyl bisphenol F (TMBPF)<smiles>Cc1cc(-c2cc(C)c(O)c(C)c2)cc(C)c1O</smiles>

Tetramethyl biphenol (TMBP)

Figure 2. Structures of biphenols. 
DFBP (114.56g, $0.525 \mathrm{~mol})$ was dissolved in $50 \%$ fuming sulfuric acid $(210 \mathrm{~mL})$ in a three-necked flask equipped with a mechanical stirrer, a thermometer, a condenser tube and a nitrogen inlet/outlet. The solution was heated at $100^{\circ} \mathrm{C}$ for $12 \mathrm{~h}$. The resultant was added to ice water $(1000 \mathrm{~g})$ and neutralized with $\mathrm{NaOH}(210 \mathrm{~g})$. Next, $\mathrm{NaCl}(210 \mathrm{~g})$ was added and the mixture was heated to obtain a clear solution. After cooling, the resulting suspension was allowed to stand over night. The white precipitated crystals were filtered out and then deionized water $(400 \mathrm{~mL})$ and ethanol $(400 \mathrm{~mL})$ were added. The mixture was heated, dissolved, and air-cooled for carrying out the recrystallization. The precipitated crystals were filtered out and then dried at $100^{\circ} \mathrm{C}$ for $6 \mathrm{~h}$ to obtain white crystals of the disodium salt of DSDFBP (yield of 70\%), which was identified with ${ }^{1} \mathrm{H}-\mathrm{NMR}$ spectroscopy, and the atomic composition was confirmed by elemental analysis.

\section{Synthesis of Sulfonated Poly (aryl ether ketone) Copoly- mers with DSDFBP}

In this study, we used three different types of biphenoles, TMBPA, TMBPF and TMBP. Even though the reactivities of biphenols were different, the copolymerization procedure was very useful as the following description. A typical copolymerization for all the sulfonated copolymers is described by the A4 series.

First, DFBP $(10.91 \mathrm{~g}, 0.050 \mathrm{~mol})$, salt-formed DSDFBP $(21.11 \mathrm{~g}, 0.050 \mathrm{~mol})$, TMBPA $(28.44 \mathrm{~g}, 0.100 \mathrm{~mol})$ and potassium carbonate $(17.30 \mathrm{~g}, 0.125 \mathrm{~mol})$ were added to a fournecked flask equipped with an overhead mechanical stirrer, a nitrogen inlet, and a Dean-Stark trap. DMSO $(250 \mathrm{~mL})$ was introduced to afford a $20 \%(\mathrm{w} / \mathrm{v})$ solid concentration. Toluene $(100 \mathrm{~mL}$, usually DMSO/toluene $=25 / 10(\mathrm{v} / \mathrm{v}))$ was used as the azeotroping agent. The reaction mixture was refluxed at $140{ }^{\circ} \mathrm{C}$ for $8 \mathrm{~h}$ to remove the water generated by proceeding copolymerization reaction. The temperature was slowly raised to $160^{\circ} \mathrm{C}$ by the controlled removal of the toluene. The reaction was allowed to proceed for $8-12 \mathrm{~h}$, during which time the solution became very viscous. The solution was cooled to $100{ }^{\circ} \mathrm{C}$ and diluted with enough DMSO to allow easier filtering. After filtering with celite to remove the salts, the copolymer was isolated by coagulation in stirred toluene and then decanted. The precipitated copolymer was washed several times with acetone to completely remove the DMSO. Finally, it was dried at $50{ }^{\circ} \mathrm{C}$ for $8 \mathrm{~h}$, and then at $150^{\circ} \mathrm{C}$ for $4 \mathrm{~h}$ under nitrogen.

The copolymers with other biphenols and compositions were prepared using similar procedures. And the sulfonation degree of polymers could be controlled easily by changing the ratio of DFBP and salt-formed DSDFBP. The sulfonation degree of polymers was represented by equivalent weight (EW, $\mathrm{g} / \mathrm{mol}$ ) value of their membranes.

\section{Membrane Preparation}

The solution of the copolymer in DMSO to afford 10-20\% transparent solution was prepared. Salt-formed membranes were prepared by casting of the solutions onto clean glass substrates, and heated to $200^{\circ} \mathrm{C}$ at the rate of $40{ }^{\circ} \mathrm{C} / \mathrm{h}$ and then dried at $200^{\circ} \mathrm{C}$ for $4 \mathrm{~h}$ under nitrogen. The thickness of the final membranes was controlled between 40 and $80 \mu \mathrm{m}$.

\section{UV Irradiation}

The UV irradiation was carried out with up to $30000 \mathrm{~mJ} /$ $\mathrm{cm}^{2}$ light using a metal halide lamp. The crosslinking reactions were confirmed indirectly by the decrease in the absorption strength of a carbonyl group in the IR measurement.

\section{Acidification of Sulfonated Copolymer Membranes}

The sulfonated polymer membranes in the salt sulfonate form were converted into the corresponding free sulfonic acid form by immersion in $1 \mathrm{~mol} / 1$ sulfuric acid for $24 \mathrm{~h}$ and followed by extraction with distilled water for $24 \mathrm{~h}$.

The acidified membranes were dried at $100^{\circ} \mathrm{C}$ for $2 \mathrm{~h}$ and at $150^{\circ} \mathrm{C}$ for $2 \mathrm{~h}$ under nitrogen. That sulfuric acid was not remained in membrane was confirmed by accordance with the measured EW values and the calculated EW values of membranes.

\section{Characterization}

${ }^{1} \mathrm{H}-\mathrm{NMR}$ spectrum of the DSDFBP was recorded for structural characterization. The data was collected with a JEOL GSX FT NMR Spectrometer using $10 \%$ solution (w/v) in $\mathrm{D}_{2} \mathrm{O}$ at room temperature. The monomer purity was analyzed by NMR spectroscopy.

The EW of the membrane was estimated by acid-base titration. Pieces of each protonated membranes were placed in $1 \mathrm{~mol} / \mathrm{l} \mathrm{NaCl}$ solutions for $24 \mathrm{~h}$. The solution was then titrated with $0.01 \mathrm{~mol} / 1 \mathrm{NaOH}$ solution using phenolphthalein as indicator. Triple titrations of each membrane were made in order to ensure accurate data. The EW value was calculated from the titration results as the ratio of the number of mole of consumed $\mathrm{NaOH}$ to the weight of dried membrane sample. The EW value was estimated as:

$$
\mathrm{EW}=W_{\text {dry }} /(0.01 \times(\mathrm{m} / 1000)) \mathrm{g} / \mathrm{mol}
$$

where $W_{\text {dry }}$ is the weight $(\mathrm{g})$ of dry membrane, 0.01 is the molar concentration of $\mathrm{NaOH}$ solution $(\mathrm{mol} / \mathrm{l})$ and $\mathrm{m}$ is the titration quantity $(\mathrm{ml})$.

\section{Water Uptake and Methanol Dissolution}

The water uptake and methanol dissolution were measured about membranes of all the sulfonated PAEKs in free sulfonic acid forms. The membranes were first thoroughly dried at $100{ }^{\circ} \mathrm{C}$ for $2 \mathrm{~h}$ and at $150{ }^{\circ} \mathrm{C}$ for $2 \mathrm{~h}$ under nitrogen to a constant weight, which was then recorded. The dried membrane was then immersed in distilled water or methanol at $25^{\circ} \mathrm{C}$ and periodically weighed on an analytical balance until a constant weight was obtained. Typically, the apparent equilibrium of water absorption or methanol dissolution occurred within $24 \mathrm{~h}$. The water uptake is reported as a percentage and estimated as follows:

Water uptake $=\left(W_{\text {wet }}-W_{\text {dry }}\right) /\left(W_{\text {dry }}\right) \times 100 \%$ 
where $W_{\text {wet }}$ and $W_{\text {dry }}$ are the weights of the wet and the dry membranes, respectively. The methanol dissolution is reported as a percentage and determined as follows:

$$
\text { Methanol dissolution }=\left(W_{1}-W_{2}\right) /\left(W_{1}\right) \times 100 \%
$$

where $W_{1}$ and $W_{2}$ are the weights of the membranes before and after soaking in methanol, respectively.

\section{Thermogravimetrical Analysis (TGA)}

The thermogravimetrical behavior of both the salt-formed and the acid-formed copolymers was performed using a TGA50 (manufactured by Shimadzu Corporation). The samples were pieces of thin membranes and had a weight total of 10$15 \mathrm{mg}$. The samples were evaluated over the range of 30$900{ }^{\circ} \mathrm{C}$ at the heating rate of $10^{\circ} \mathrm{C} / \mathrm{min}$ in air.

\section{Proton Conductivity}

Membranes of sulfonated PAEKs were cut into a $5 \mathrm{~mm}$ width and a $40 \mathrm{~mm}$ length, then positioned on a PTFE folder and four electrodes were pressure-joined to measure the resistivity from a circular arc obtained by the AC impedance method using the 4 terminal method. The interval between the voltage terminals was $20 \mathrm{~mm}$. The impedance was measured using an LCR meter (3532, a product of Hioki E.E. Corporation). The temperature was held at $90{ }^{\circ} \mathrm{C}$ while an electrodeconnected sample was put in a thermostatic chamber made of aluminum block to measure the conductivity. The humidity was supplied into the thermostatic chamber at atmospheric pressure by flowing vapor generated by heating the distilled water at the temperature of the thermostatic chamber $+5{ }^{\circ} \mathrm{C}$ with a vapor generator. Furthermore, the membrane thickness was measured with a micrometer in the dried form.

\section{Methanol Permeation Rate}

At room temperature, the distilled water and an $1 \mathrm{~mol} / 1$ methanol aqueous solution came into contact with each other via the sulfonated PAEKs membrane having a diameter of $23 \mathrm{~mm}$ to measure the concentration change in methanol of the distilled water side using a refractive index meter (RID-6A, manufactured by Shimadzu Corporation). The methanol permeation rate was calculated at the membrane thickness of $50 \mu \mathrm{m}$ from the slope of the straight line of the increase in the obtained methanol concentrations.

\section{Hot Water Test ${ }^{12}$}

The stability toward water of crosslinking structures was examined by the hot water test. F2 membrane was soaked in distilled water at $85^{\circ} \mathrm{C}$ for $8,15,30$ and $50 \mathrm{~h}$. The stability was evaluated by comparing the values of before and after the test about its weight change, water uptake and proton conductivity. The weight change is reported as a percentage and estimated as follows:

$$
\text { Weight change }=\left(W_{\text {before }}-W_{\text {after }}\right) /\left(W_{\text {before }}\right) \times 100 \%
$$

where $W_{\text {before }}$ and $W_{\text {after }}$ are the dried weights of the before and the after the hot water test.

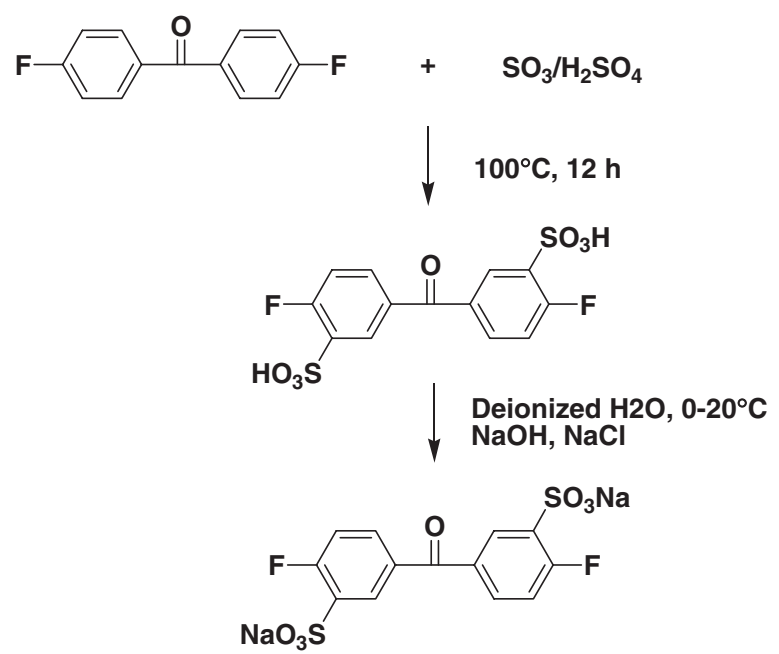

Figure 3. Synthesis of disodium salts of DSDFBP.

\section{RESULTS AND DISCUSSION}

\section{Monomer Synthesis}

A monomer, DSDFBP, was synthesized by direct sulfonation of DFBP in fuming sulfuric acid as shown in Figure 3. Salt-formed DSDFBP with high purity was obtained in a good yield $(70 \%)$ after recrystallizing from a methanol/water mixture. The sulfonation occurred at the 3,3'-positions of the phenyl-rings because these positions are more active than others. The ${ }^{1} \mathrm{H}-\mathrm{NMR}$ spectrum and the element analysis of saltformed DSDFB confirmed the chemical structure of the product.

\section{Copolymer Synthesis}

The polycondensation reaction is depicted in Figure 4. The PEM of DMFC requires a high molecular weight for flexibility and high strength. Careful dehydration with toluene was important for the high molecular weight, which was recognized by high intrinsic viscosity. High temperature was required with the less reactive sterically hindered DSDFBP monomer. This polymerization proceeded smoothly and the procedure has been successfully applied to use with TMBPF and TMBP.

The intrinsic viscosities of the sulfonated PAEK copolymers, the calculated EW values and the observed EW values are shown in Table I. The intrinsic viscosity obtained $0.8-$ $1.7 \mathrm{dl} / \mathrm{g}$ and were high enough to make membranes. Their intrinsic viscosities were not affected by biphenol structures and degrees of sufonation. The mole ratio of DFBP and DSDFBP can adjust the desired EW value. The observed EW value accorded with the calculated EW value well. The agreement of the observed EW value and the calculated EW value proved that sulfuric acid used for acidification of membrane did not remain in membranes. In addition, this agreement shows that the sulfonic acid sodium groups are stable during the reaction at $160^{\circ} \mathrm{C}$ and the dry at $200^{\circ} \mathrm{C}$. 


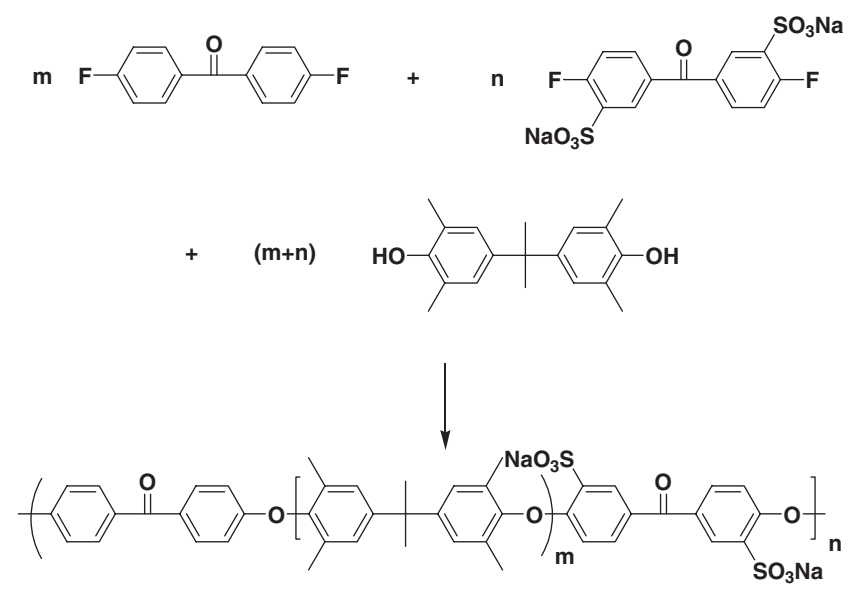

Figure 4. Synthesis of random TMBPA-based sulfonated poly (aryl ether ketone) copolymer.

Table I. Sample codes and structures of poly (aryl ether ketone)s

\begin{tabular}{clccc}
\hline $\begin{array}{c}\text { Sample } \\
\text { Codes }\end{array}$ & \multicolumn{1}{c}{ Monomer composition } & $\begin{array}{c}\eta_{\text {inh }}{ }^{\mathrm{a}} \\
(\mathrm{dl} / \mathrm{g})\end{array}$ & $\begin{array}{c}\mathrm{EW}^{\mathrm{b}} \\
(\mathrm{g} / \mathrm{mol})\end{array}$ & $\begin{array}{c}\mathrm{EW}^{\mathrm{c}} \\
(\mathrm{g} / \mathrm{mol})\end{array}$ \\
\hline A1 & DSDFBP/DFBP/TMBPA $=10 / 0 / 10$ & 0.9 & 311 & - \\
A2 & DSDFBP/DFBP/TMBPA $=9 / 1 / 10$ & 0.8 & 335 & - \\
A3 & DSDFBP/DFBP/TMBPA $=8 / 2 / 10$ & 0.8 & 369 & - \\
A4 & DSDFBP/DFBP/TMBPA $=5 / 5 / 10$ & 0.8 & 543 & - \\
A5 & DSDFBP/DFBP/TMBPA $=3.5 / 6.5 / 10$ & 0.8 & 741 & 765 \\
F1 & DSDFBP/DFBP/TMBPF $=5 / 5 / 10$ & 1.1 & 514 & - \\
F2 & DSDFBP/DFBP/TMBPF $=3.5 / 6.5 / 10$ & 1.1 & 701 & 742 \\
B1 & DSDFBP/DFBP/TMBP $=4.5 / 5.5 / 10$ & 1.7 & 547 & - \\
B2 & DSDFBP/DFBP/TMBP $=3 / 7 / 10$ & 1.3 & 781 & 805 \\
\hline
\end{tabular}

a Inherent viscosity was measured at a concentration of $0.5 \%$ in DMSO at $35{ }^{\circ} \mathrm{C}$. ${ }^{b}$ Calculated value. ${ }^{c}$ Determined by acid-base titration with $\mathrm{NaOH}$ solution.

\section{Membrane Preparation and Characterization}

UV Irradiation. The flexible and durable membranes were crosslinked by UV irradiation to improve not only methanol permeability but also solvent dissolution. As shown in Figure 1, a radical on the benzophenone generated at the first stage of an irradiation with UV pulls out hydrogen from a methyl group. Subsequently, the crosslinking is carried out by dimerization of a benzyl radical, a coupling reaction of the benzyl radical with an alcohole carbon radical or dimerization of an alcohole carbon radical. These crosslinking reactions were confirmed indirectly by the decrease in the absorption strength of a carbonyl group in the IR measurement. The UV irradiation caused the drying and the shrinkage of a membrane, therefore UV had to be irradiated in $1000 \mathrm{~mJ} / \mathrm{cm}^{2}$ repeatedly to prevent transformation of a membrane. Figure 5 shows the absorption strength change of carbonyl groups of A4 membrane by the UV irradiation. This figure shows that as the quantity of the UV irradiation increased, the absorption strength of carbonyl groups decreased. About half of carbonyl groups can finally contribute to the crosslinking reaction.

The absorption strength change of carbonyl groups of A4, F1 and B1 membranes, which have similar EW values, is shown in Figure 6. This figure shows that the crosslinking degree of A4, F1 and B1 membranes were different by each

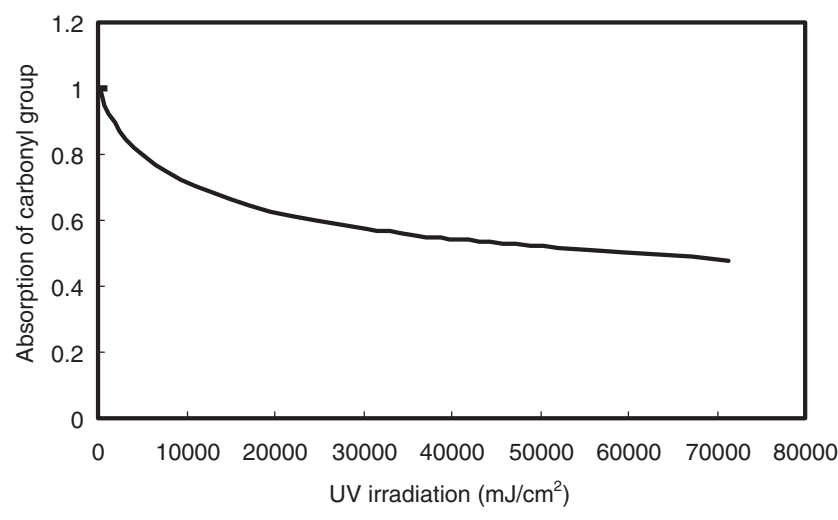

Figure 5. UV irradiation dependence of absorption of carbonyl group of A4

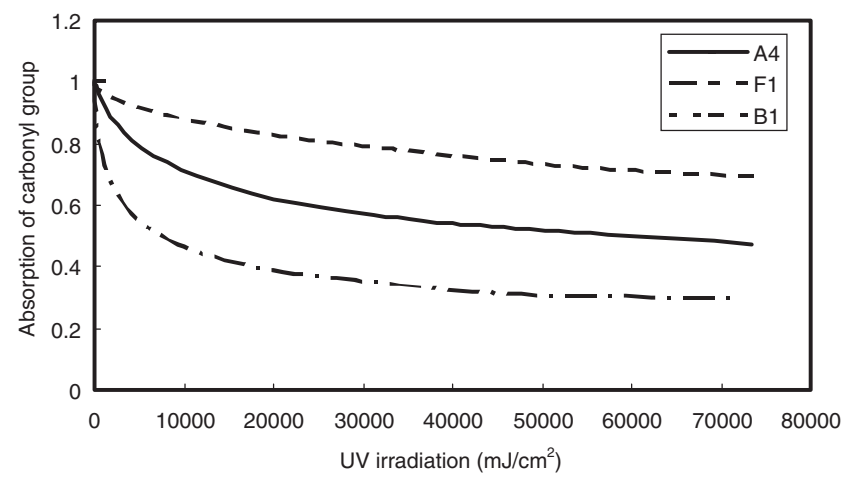

Figure 6. UV irradiation dependence of absorption of carbonyl group of sulfonated PAEKs.

and the crosslinking degree of $\mathbf{F 1}$ membrane was the highest. The IR absorption spectra of the methyl groups and the carbonyl groups in A4, F1 and B1 membranes are shown in Figures 7-9, respectivily. As the crosslinking system is shown in Figure 1, the change of IR absorption strengths of the methyl groups and the carbonyl groups should be at the same rate. However, the decrease rate of absorption of the carbonyl groups was faster than that of the methyl groups for F1 membrane. This difference shows that the carbonyl groups crosslinked with other unit except the methyl group, the methylene group of the F1 structure. The crosslinking degree of F1 was the highest in these three structures because F1 structure has two crosslinkable units that are the methyl groups and the methylene groups.

\section{TGA}

The thermo-oxidative stability of the crosslinked membranes was measured by the weight reduction temperature in air, using TGA at heating rate of $10^{\circ} \mathrm{C} / \mathrm{min}$. The TGA result of A4 is shown in Figure 10. This figure shows that the weight didn't change until $240^{\circ} \mathrm{C}$ apart from decrease of water, which was taken in membrane as moisture. Moreover, the result of using a TGA coupled to mass spectrometry (MS) showed that sulfone acid groups came off at first at about $250^{\circ} \mathrm{C}$. The thermo-oxidative stabilities of other polymers were similar with A4. Each $T_{\mathrm{d} 1}$ are shown in Tables II and III. The thermo- 


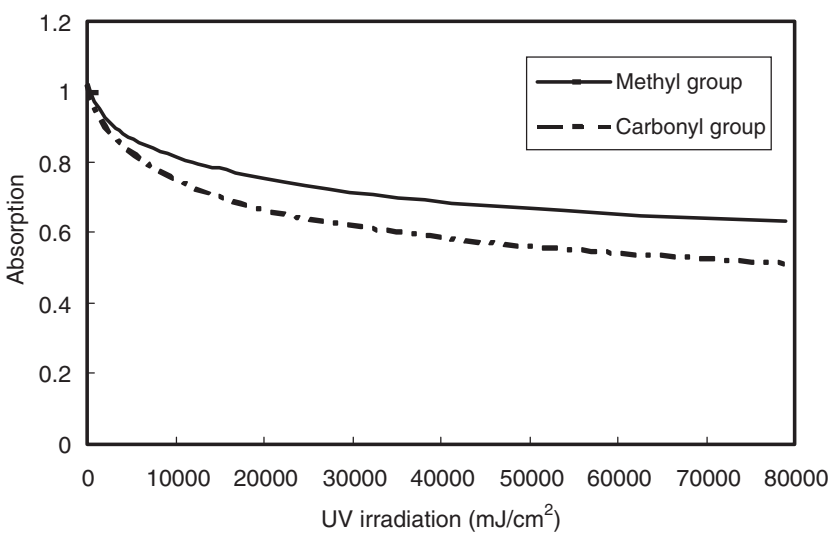

Figure 7. UV irradiation dependence of absorption of methyl group and carbonyl group of A4.

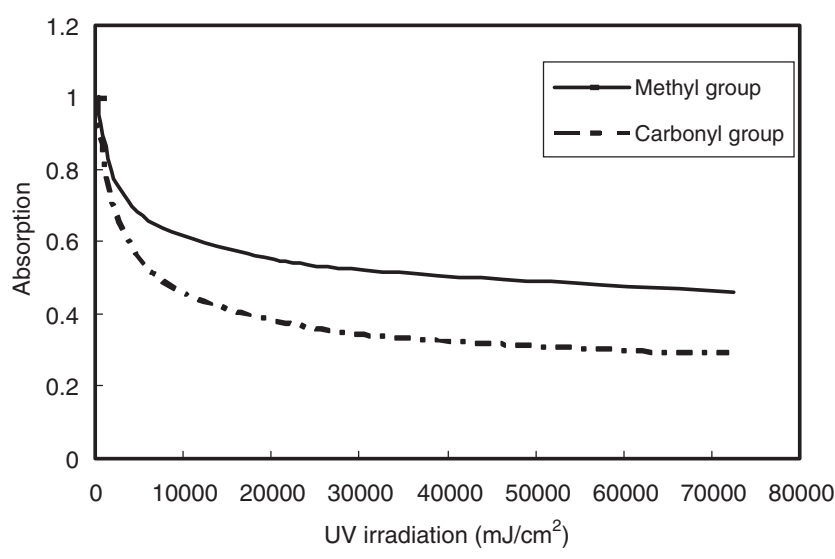

Figure 8. UV irradiation dependence of absorption of methyl group and carbonyl group of $\mathrm{F} 1$.

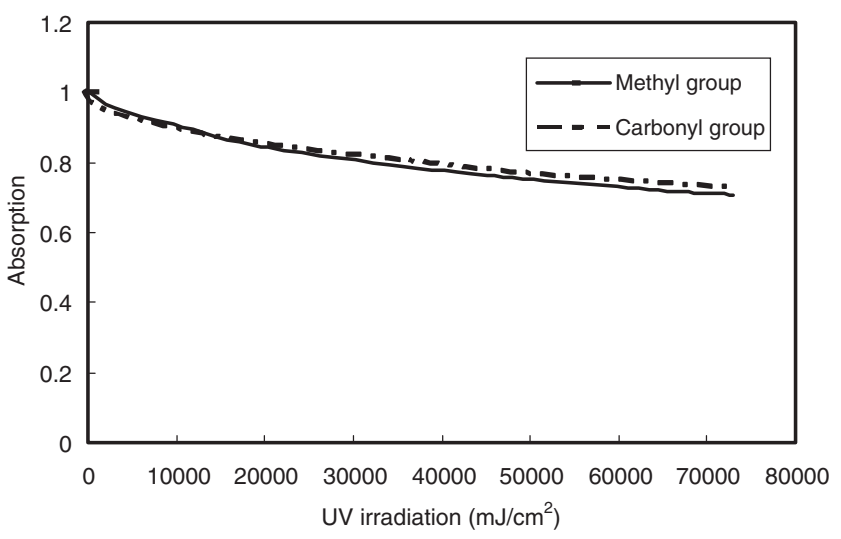

Figure 9. UV irradiation dependence of absorption of methyl group and carbonyl group of B1.

oxidative stabilities of $\mathbf{A 4}$ and the other polymers were sufficient to use in the DMFC. The UV irradiation didn't decrease stability of the membranes.

\section{Water Uptake and Methanol Dissolution}

Measuring the water uptakes of PEMs is very important,

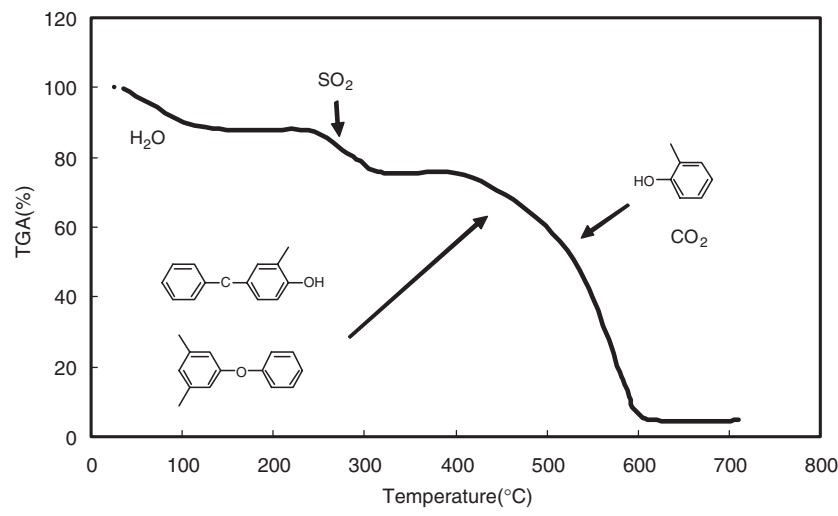

Figure 10. TGA thermogram of crosslinked A4 membrane in air at $10^{\circ} \mathrm{C} / \mathrm{min}$.

Table II. UV irradiation dependence of properties of A4

\begin{tabular}{cccccc}
\hline $\begin{array}{c}\text { UV } \\
\text { irradiation } \\
\left(\mathrm{mJ} / \mathrm{cm}^{2}\right)\end{array}$ & $\begin{array}{c}\text { Water } \\
\text { uptake }^{\mathrm{a}} \\
(\%)\end{array}$ & $\begin{array}{c}\text { Proton } \\
\text { conductivity } \\
(\mathrm{S} / \mathrm{cm})\end{array}$ & $\begin{array}{c}\text { Methanol } \\
\text { permeation rate } \\
\left(\mu \mathrm{mol} / \mathrm{cm}^{2} / \mathrm{min}\right)\end{array}$ & $\begin{array}{c}\text { Methanol } \\
\text { dissolution }^{\mathrm{d}} \\
(\%)\end{array}$ & $\begin{array}{c}T_{\mathrm{d} 1} \mathrm{e} \\
\left({ }^{\circ} \mathrm{C}\right)\end{array}$ \\
\hline 1000 & 45 & 0.15 & 6.6 & 73 & 245 \\
5000 & 43 & 0.17 & 5.3 & 46 & 242 \\
10000 & 64 & 0.15 & 4.7 & 37 & 239 \\
15000 & 35 & 0.14 & 5.2 & 11 & 239 \\
30000 & 31 & - & - & 11 & - \\
\hline
\end{tabular}

at $25^{\circ} \mathrm{C} .{ }^{\mathrm{b}}$ At $90^{\circ} \mathrm{C}$ and under humidification $(100 \% \mathrm{RH}) .{ }^{\mathrm{c}} \mathrm{At} 25^{\circ} \mathrm{C}$ and with $1 \mathrm{~mol} / \mathrm{l}$ methanol. ${ }^{\mathrm{d}}$ At $25^{\circ} \mathrm{C}$ and in $100 \%$ methanol. ${ }^{\mathrm{e}} 1 \%$ weight loss temprerature measured by $\mathrm{TGA}$ in air at $10^{\circ} \mathrm{C} / \mathrm{min}$ heating rate.

Table III. Properties of sulfonated PAEKs after $15000 \mathrm{~mJ} / \mathrm{cm}^{2}$ UV irradiation

\begin{tabular}{ccccccc}
\hline $\begin{array}{c}\text { Sample } \\
\text { Code }\end{array}$ & $\begin{array}{c}\mathrm{EW}^{\mathrm{a}} \\
(\mathrm{g} / \mathrm{mol})\end{array}$ & $\begin{array}{c}\text { Water } \\
\text { uptake }^{\mathrm{b}} \\
(\%)\end{array}$ & $\begin{array}{c}\text { Proton } \\
\text { conductivity } \\
(\mathrm{S} / \mathrm{cm})\end{array}$ & $\begin{array}{c}\text { Methanol } \\
\text { permeation rate } \\
\left(\mu \mathrm{mol} / \mathrm{cm}^{2} / \mathrm{min}\right)\end{array}$ & $\begin{array}{c}\text { Methanol } \\
\text { dissolution }^{\mathrm{e}} \\
(\%)\end{array}$ & $\begin{array}{c}T_{\mathrm{d} 1}{ }^{\mathrm{f}} \\
\left({ }^{\circ} \mathrm{C}\right)\end{array}$ \\
\hline A4 & 543 & 35 & 0.14 & 5.2 & 11 & 239 \\
F1 & 515 & 40 & 0.23 & 5.5 & 0 & 342 \\
F2 & 701 & 19 & 0.10 & 2.1 & 0 & - \\
B1 & 547 & 41 & 0.11 & 5.2 & 7 & 258 \\
B2 & 781 & 16 & 0.09 & 2.5 & 0 & - \\
\hline
\end{tabular}

${ }^{a}$ Calulated value. ${ }^{b}$ At $25^{\circ} \mathrm{C}$. ${ }^{\mathrm{c}}$ At $90^{\circ} \mathrm{C}$ and under humidification $(100 \%$ $\mathrm{RH}) .{ }^{\mathrm{d}}$ At $25^{\circ} \mathrm{C}$ and with $1 \mathrm{~mol} / \mathrm{l}$ methanol. ${ }^{\mathrm{e}} \mathrm{At} 25^{\circ} \mathrm{C}$ and in $100 \%$ methanol. ${ }^{\mathrm{f}} 1 \%$ weight loss temperature measured by $\mathrm{TGA}$ in air at $10^{\circ} \mathrm{C} / \mathrm{min}$ heating rate.

since the proton conductivity is influenced a great deal by the presence of water. Moreover characterizing the behaviors of PEMs in contact with methanol is very important, since the higher density of methanol aqueous solution is necessary to larger energy capacity of DMFC.

The relationship between the water uptakes and the quantity of UV irradiation to A4 membrane are shown in Table II. As the quantity of UV irradiation increased, the water uptakes were degreased. The water uptakes of other A-polymer membranes, F-polymer membranes and $\mathbf{B}$-polymer membranes are shown in Table III. Figure 11 shows the relationship between the EW values and the water uptakes of $15000 \mathrm{~mJ} /$ $\mathrm{cm}^{2}$ UV irradiation. When the EW values were similar and the quantity of UV irradiation was the same, the water uptakes 


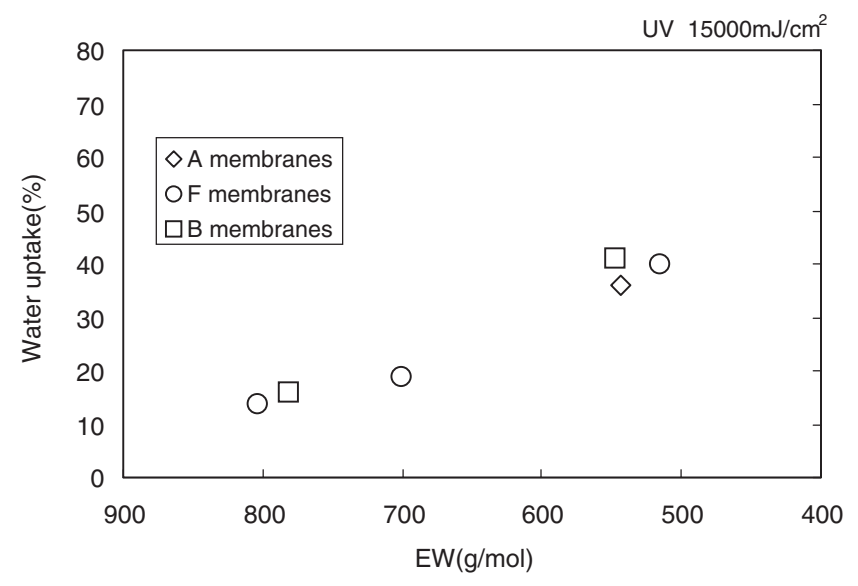

Figure 11. EW dependence of water uptake for sulfonated PAEKs.

Table IV. Methanol dissolution of A-polymer membranes

\begin{tabular}{ccc}
\hline \multirow{2}{*}{$\begin{array}{c}\text { Sample } \\
\text { Code }\end{array}$} & \multicolumn{2}{c}{ Methanol dissolution $^{\mathrm{a}}(\%)$} \\
\cline { 2 - 3 } & $0 \mathrm{~mJ} / \mathrm{cm}^{2 \mathrm{~b}}$ & $6000 \mathrm{~mJ} / \mathrm{cm}^{2 \mathrm{~b}}$ \\
\hline A1 & 100 & 100 \\
A2 & 100 & 55 \\
A3 & 100 & 51 \\
A4 & 100 & 22 \\
A5 & 56 & 1 \\
\hline
\end{tabular}

${ }^{\text {a At }} 25^{\circ} \mathrm{C}$. ${ }^{\mathrm{b}} \mathrm{UV}$ irradiation quantity.

were similar in these similar type polymer membranes of PAEK structures. This result was shown in Figure 11.

The methanol dissolutions of the A-polymer membranes are summarized in Table II. The copolymers, which had DSDFBP/DFBP/TMBPA mole ratio of 10/0/10, 9/1/10, 8/ $2 / 10$ and $5 / 5 / 10$, were soluble in methanol, but the UV irradiation to these membranes improved their methanol soluble resistance. The crosslinking of PAEK membranes by the UV irradiation was very effective to improve the methanol dissolution clearly. The relationship of the properties of the A4 membranes and the quantity of the UV irradiation are shown in Table IV. As the quantity of UV irradiation increased, and the crosslinking reaction occurred, the dissolution in methanol was supressed. The relationship between the UV irradiation quantity and the solubility in methanol is shown in Figure 12. When the quantity of UV irradiation was over $15000 \mathrm{~mJ} / \mathrm{cm}^{2}$, the solubility became almost constant. About half of the crosslinkable groups contribute to crosslinking reaction as shown in Figure 6, and the crosslinking reaction almost reacted until irradiation of $15000 \mathrm{~mJ} / \mathrm{cm}^{2}$. The methanol dissolutions of F-polymer membranes and B-polymer membranes are shown in Table III. At the same quantity of UV irradiation and the similar value of EW, for example A4, F1 and B1, the methanol dissolutions were different greatly in each structure. The methanol dissolution of each EW values and structure are shown in Figure 13. The methanol dissolution characteristics had structure dependence and F-polymer structure had the lowest solubility. The lowest solubility was caused by the high crosslinking degree of $\mathbf{F}$-polymer structure.

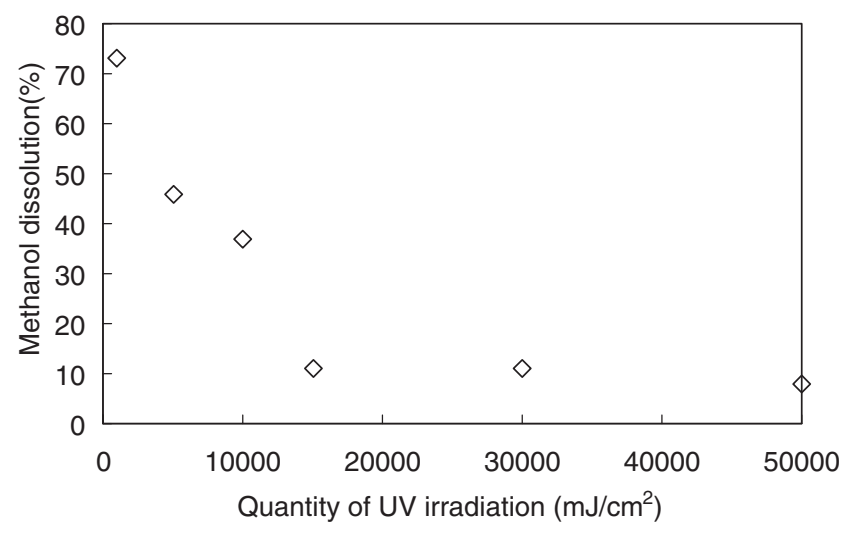

Figure 12. UV irradiation dependence of methanol dissolution of A4.

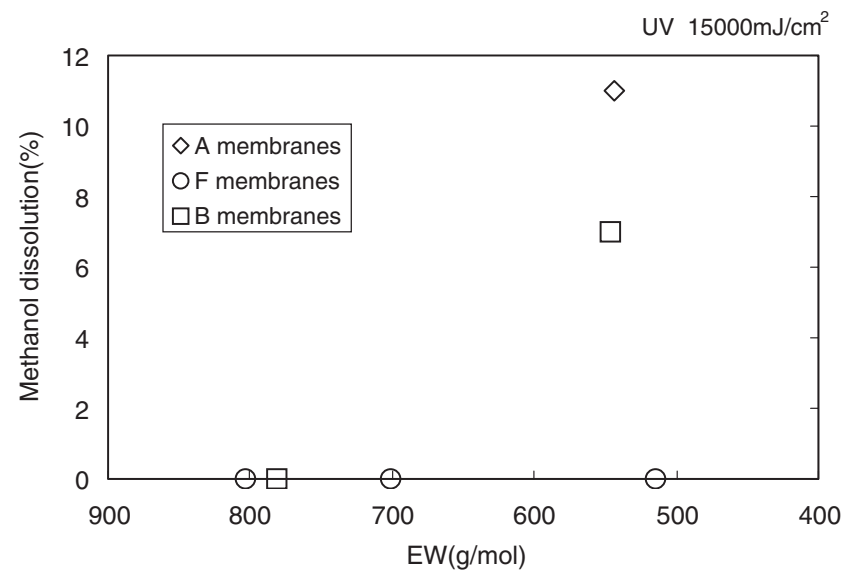

Figure 13. EW dependence of methanol dissolution for sulfonated PAEKs.

\section{Proton Conductivity}

Table II shows the relationship between the quantity of UV irradiation and the proton conductivity. The quantity of UV irradiation didn't affect the proton conductivity with these ranges. The proton conductivities of the sulfonated PAEKs are shown in Table III. The EW dependence of the proton conductivity is shown in Figure 14. In these similar structures of PAEKs, the change of proton conductivity was dependent on EW value without being dependent on structure of a polymer. The proton conductivities of these sulfonated PAEKs were in the same range as reported for other sulfonated aromatic polymers and their values were high enough to be used in DMFCs.

\section{Methanol Permeation Rate}

The methanol permeation rate also decreased as the crosslinking increased as shown in Table II. Crosslinking membrane limits swelling of membrane with water. When a membrane swells with water, a channel of water is formed in a membrane. Methanol goes through this channel with water and methanol crossover occurs. Therefore, swelling limit of a membrane by crosslinking is very effective to protect methanol crossover. As shown in Table III and Figure 15, in these similar structures of PAEKs, the methanol permeation rates are dependent on the 


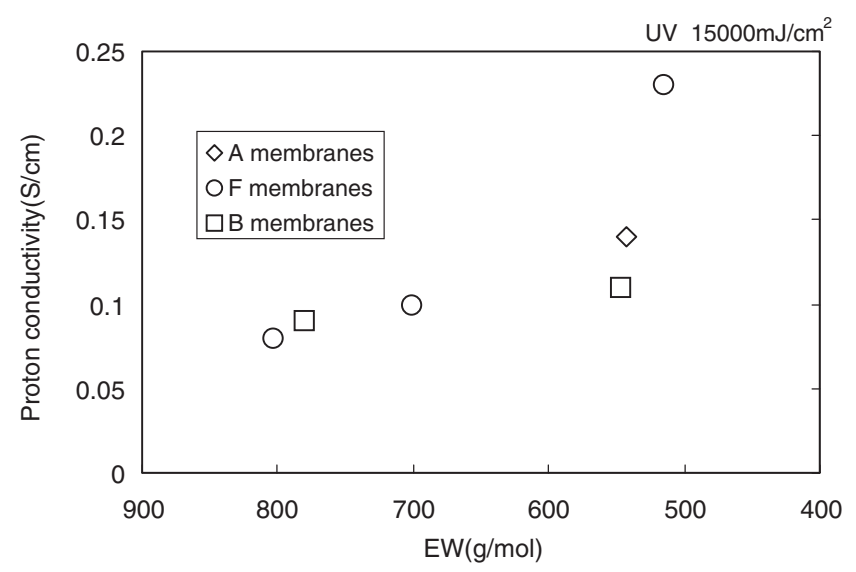

Figure 14. EW dependence of proton conductivity for sulfonated PAEKs.

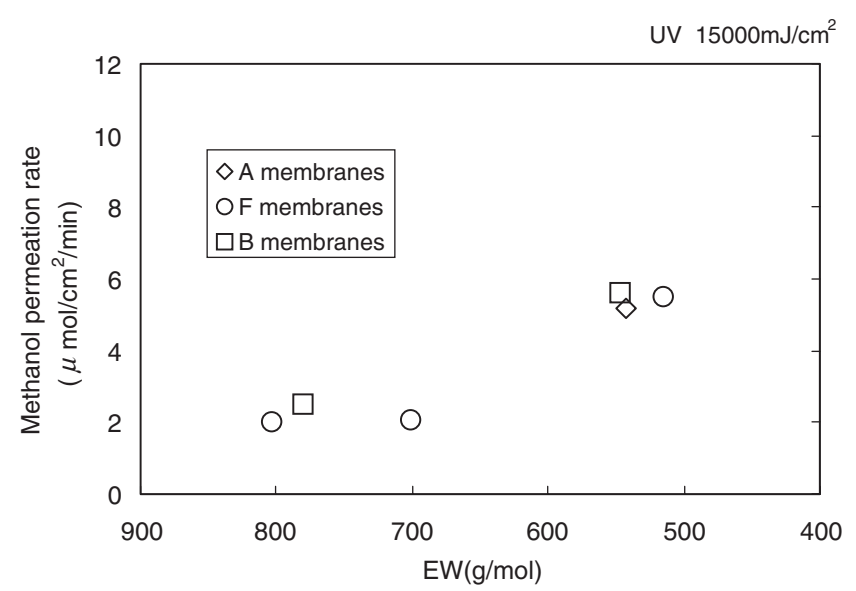

Figure 15. EW dependence of methanol permeation rate for sulfonated PAEKs.

EW value without depending on their structure, same as the water uptake and the proton conductivity. If the EW value significantly increases, the values of these properties decrease. Therefore, selecting the optimized quantity of UV irradiation is important to maintain the balance of all properties. The UV irradiation of $15000 \mathrm{~mJ} / \mathrm{cm}^{2}$ is the most suitable in these sulfonated PAEKs.

\section{Hot Water Test}

The hot water test was done in order to examine the stability toward water of the crosslinking structure. The result of hot water test of $\mathbf{F 2}$ membrane is shown in Table V. There was no particular change with its weight change, water uptake and proton conductivity of before and after soaking in water at $85^{\circ} \mathrm{C}$ for $8,15,30$ and $50 \mathrm{~h}$. This shows that the crosslinking structure of $\mathbf{F 2}$ membrane is stable in water.

\section{CONCLUSIONS}

1. An improved method was developed for preparing the saltformed DSDFBP monomer in high yield. A new class of sulfonated PAEKs was synthesized via the direct copolymer-
Table V. Hot water test of F2 membrane

\begin{tabular}{ccccc}
\hline $\begin{array}{c}\text { Soaking } \\
\text { Time }^{\mathrm{a}} \\
(\mathrm{h})\end{array}$ & Appearance $^{\mathrm{b}}$ & $\begin{array}{c}\text { Weight } \\
\text { change }^{\mathrm{c}} \\
(\%)\end{array}$ & $\begin{array}{c}\text { Water }^{\text {uptake }} \\
(\%)\end{array}$ & $\begin{array}{c}\text { Proton } \\
\text { conductivity } \\
(\mathrm{S} / \mathrm{cm})\end{array}$ \\
\hline 0 & & 0.0 & 24 & 0.10 \\
8 & $\mathrm{~N}$ & 0.6 & 28 & 0.10 \\
15 & $\mathrm{~N}$ & 0.3 & 25 & 0.09 \\
30 & $\mathrm{~N}$ & 0.5 & 26 & 0.11 \\
50 & $\mathrm{~N}$ & -0.4 & 22 & 0.09 \\
\hline
\end{tabular}

${ }^{\text {a At }} 85^{\circ} \mathrm{C}$ in water. ${ }^{\mathrm{b}} \mathrm{N}$ :no change. ${ }^{\mathrm{c}}\left(W_{\text {before }}-W_{\text {after }}\right) / W_{\text {before }} \times 100 \%$. ${ }^{\mathrm{d}} \mathrm{At}$ $25^{\circ} \mathrm{C}$. ${ }^{\mathrm{e}}$ At $90^{\circ} \mathrm{C}$ and under humidification $(100 \% \mathrm{RH})$.

ization of the disulfonated dihalide benzophenone monomers with DFBP and any of three different biphenols. Varying the stoichiometric ratio of the DSDFBP and the DFBP easily controlled the degree of sulfonation in the copolymers.

2. These sulfonated PAEKs having benzophenone groups and methyl groups in their structures were easily crosslinked by UV irradiation. This crosslinking can improve the methanol blocking properties, methanol dissolution and methanol permission rate, required as the important properties for the DMFCs.

3. The F-polymer structure shows high crosslinking characteristic because of having crosslinkable methylene groups in its structure besides methyl groups.

4. Especially the crosslinked F1, consistng of DSDFBP/ $\mathrm{DFBP} / \mathrm{TMBPF}=5 / 5 / 10$, in these sulfonated PAEKs has an excellent property as the PEM for DMFC. Its proton conductivity was $0.23 \mathrm{~S} / \mathrm{cm}$ at $90^{\circ} \mathrm{C}$, the methanol permeation rate was $5.5 \mu \mathrm{mol} / \mathrm{cm}^{2} / \mathrm{min}$ and it was not dissolved in methanol. This proton conductivity and methanol permeability are comparable to and half of the values of fluorinated copolymer Nafion $112^{\circledR}$ that is known as the representative material of a PEM of DMFC respectively.

Received: March 1, 2007 Accepted: September 22, 2007 Published: November 13, 2007

\section{REFERENCES}

1. T. Yamaguchi, F. Miyata, and S. Nakao, J. Membr. Sci., 214, 283 (2003).

2. S. S. Yen, US Patent 18823 (1996).

3. L. E. Karlsson and P. Jannasch, J. Membr. Sci., 230, 61 (2004).

4. M. Yoshida, JP Patent 2005-336338 (2005).

5. J. P. Quentin, US Patent 3709841 (1973).

6. J. B. Baradie, C. Poinsignon, J. Y. Sanchez, J. Piffard, G. Vitter, N. Bastaoui, D. Forcallo, A. Denoyelle, D. Delabouglise, and M. Vaujany, J. Power Sources, 74, 8 (1998).

7. C. Bailly, D. J. Williams, F. E. Karasz, and W. J. MacKnight, Polymer, 28, 1009 (1987).

8. M. T. Bishop, F. Karasz, P. S. Russo, and K. H. Langley, Macromolecules, 18, 86 (1985).

9. A. Noshay and L. M. Robeson, J. Appl. Polym. Sci., 20, 1885 (1976).

10. F. Wang, T. Chen, and J. Xu, Macromol. Chem. Phys., 199, 1421 (1998).

11. K. Goto, J. Kamada, J. Kida, and S. Tamai, J. Photopolym. Sci. Technol., 17, 215 (2004).

12. X. Guo, J. Fang, T. Watari, K. Tanaka, H. Kita, and K. Okamoto, Macromolecules, 35, 6707 (2002). 